\title{
Size effect in self consolidating concrete beams with and without notches
}

\author{
H ESKANDARI $^{1, *}$, S MURALIDHARA ${ }^{2,3}$, B K RAGHU PRASAD ${ }^{3}$ \\ and $\mathrm{B} \mathrm{V}$ VENKATARAMA REDDY ${ }^{3}$ \\ ${ }^{1}$ Department of Civil Engineering, Sabzevar Tarbiat Moallem University, \\ Sabzevar, Iran \\ ${ }^{2}$ Department of Civil Engineering, BMS College of Engineering, \\ Bangalore 560004 \\ ${ }^{3}$ Department of Civil Engineering, Indian Institute of Science, Bangalore 560012 \\ e-mail: Hamidiisc@yahoo.com
}

MS received 1 April 2009; revised 25 November 2009; accepted 13 January 2010

\begin{abstract}
The aim of this study is to obtain the fracture characteristics of low and medium compressive strength self consolidating concrete (SCC) for notched and un-notched plain concrete beams by using work of fracture $G_{F}$ and size effect model $G_{f}$ methods and comparing them with those of normal concrete and high performance concrete. The results show that; (i) with an increase in compressive strength, $G_{F}$ increases and $G_{f}$ decreases; (ii) with an increase in depth of beam, the decrease in nominal stress of notched beam is more when compared with that of a notchless beam.
\end{abstract}

Keywords. Size effect model; self consolidating concrete; notched beam.

\section{Introduction}

Self-consolidating concrete (SCC) is the hot topic of current research area today. Many intrinsic properties of the concrete are yet to be understood clearly. Concrete is prepared by proportioning materials and adding admixtures to suit the specific requirements. Large amount of mineral admixture also called cement replacement material is used for high performance concrete (HPC) and SCC to make concrete dense and economical (Albiero 2001; Mata 2004). The differences between HPC and SCC is essentially in the use of special admixture (Kishi et al 2000) i.e. high range water reducing admixture (HRWR). The use of HRWR and viscositymodifying admixture (VMA) can provide a high degree of fluidity and segregation resistance to SCC, a distinct advantage over HPC (Bury \& Christensen 2002). Polyacrylate-based super plasticizers are more efficient to reduce the porosity of matrix (Biolzi et al 1997). Due to the use of chemical and mineral admixtures, the micro cracks studies are essential in SCC than in normal concrete (NC) (Druta 2003; Wittmann 2002).

*For correspondence 
The improved pore structure and better densification of matrix have bearing on the fracture characteristics like fracture energy $G_{F}$ and critical stress intensity factor $K_{I c}$. It has been reported that increased density will increase the compressive and tensile strengths of concrete as well as fracture energy (Giaccio et al 1993). It will decrease the characteristic length (Haidar \& Cabor 2002). Many investigators have evaluated the mechanical characteristics and durability of SCC mixes. SCC is more porous and has lesser density compared to HPC.

Fracture behaviour of plain concrete is the basis for all the studies on behaviour of reinforced concrete and pre-stressed concrete structures via fracture mechanics. Experimental studies conducted by many researchers show that, with increase in the size of aggregate, there is a decrease in the brittleness of hardened concrete and increase in both the fracture energy as well as the fracture toughness of concrete (Amparano et al 2000; Appa Rao \& Raghu Prasad 2002; Strange \& Bryant 1979).

As pointed out by Bazant \& Pfeiffer (1987); Bazant \& Kazemi (1990), the fracture energies $G_{F}$ and $G_{f}$ are two different material characteristics. The fracture energy $G_{F}$ is obtained by the area under the complete load-deflection curve, and the fracture energy $G_{f}$ is represented by the area under the initial tangent of the softening curve. It has been shown that the fracture energy $G_{f}$ (Bazant \& Giraudon 2002; Ta-Peng \& Mei-Miao 1996; Perdikaris \& Romeo 1995) increases with increasing in compressive strength. Notchless beams have not been tested sufficiently in the past. A very few experimental results are available (Karihaloo \& Xiao 2002; Kim \& Eo 1990) on notchless beams. Determination of fracture characteristics of geometrically similar beams with and without notches are of particular interest for SCC.

\section{Research significance}

There are many studies on fracture characteristics of notched beams and only a few on notchless beams in literature. The present study is aimed at documenting effects of size both in notch and notchless beams in SCC using size effect model. The objectives of the present work are listed below:

(i) The influence of notch on fracture characteristics such as fracture energies $G_{F}, G_{f}, K_{I c}$, critical energy release rate $\left(G_{I c}\right)$ and characteristic length $\left(l_{c h}\right)$ in SCC beams under three point bend condition.

(ii) Size effect model (SEM) for notched and notchless beams.

(iii) Influence of compressive strength on fracture energies $G_{F}$ and $G_{f}$.

(iv) Effect of notch on brittleness of concrete structure.

\section{Evaluation of fracture characteristics}

\subsection{Size effect model (SEM)}

In the method proposed by Bazant \& Pfeiffer (1987), the fracture energy is determined from the size effect model. If geometrically similar beams are used and loaded up to rupture and extrapolated to a beam of infinite dimensions, the fracture energy must have one single value, regardless of the type, size or shape of the specimen. Bazant and Pfeiffer suggested the following relationship:

$$
\sigma_{N}=\frac{B f_{t}}{\left(1+b / b_{o}\right)^{1 / 2}},
$$


where $\sigma_{N}=C_{n} \frac{P_{u}}{b d}$ is the nominal stress at failure, $f_{t}$ is the tensile strength, $P_{u}$ is the ultimate load and $C_{n}$ is a coefficient introduced for convenience.

The coefficients $B$ and $b_{o}$ are determined by linear regression. For this purpose, equation (1) applicable to geometrically similar specimens of different sizes, can be algebraically rearranged to a linear regression form $Y=A X+C$, in which:

$$
Y=\left(1 / \sigma_{N}\right)^{2} ; X=d ; b_{o}=C / A ; B=1 / \sqrt{C} .
$$

The concrete fracture process zone size is small in an infinite size specimen. In this case, the fracture energy $G_{f}$ and fracture process zone $c_{f}$ respectively for infinitely large specimens are calculated as:

$$
\begin{aligned}
G_{f} & =\frac{g(\alpha)}{A E}, \\
c_{f} & =\frac{g(\alpha)}{g^{\prime}(\alpha)} \frac{C}{A}, \\
g(\alpha) & =(S / b)^{2} \pi \alpha\left[1 \cdot 5 g_{1}(\alpha)\right]^{2} \text { and } g^{\prime}(\alpha)=d g(\alpha) / d a,
\end{aligned}
$$

where $g_{1}(\alpha)$ is shown in equation (8) for $S / b=4, E$ is the Young's modulus of elasticity of the concrete, $A$ is the angular coefficient of the linear regression plot, $g(\alpha)$ is the nondimensional energy release rate calculated according to LEFM and $\alpha$ is the relative notch to depth ratio $(a / b)$.

\subsection{Fracture energy from work-of-fracture $\left(G_{F}\right)$}

Many methods have been recommended to determine the fracture energy and characteristic length, using simple three point bending test (Mindess 1984; Petersson 1980a; Petersson 1980b; Tang et al 1996; Belhamel et al 2002; Elices et al 1997; NT Build 491,1999; Guinea et al 1992; Elices et al 1992). One can apply the recommendation of the Technical Committee RILEM (RILEM FMC-50, 1985) to perform three-point bend tests in notched beams. The Fracture energy is defined as the amount of energy necessary to create a crack of unit surface area projected in a plane parallel to the crack direction. As the beam is split into two halves, the fracture energy can be determined by dividing the total dissipated energy by the total surface area of the crack. According to the RILEM (RILEM FMT 89, 1990) fracture energy can be calculated as

$$
G_{F}=\frac{W_{0}+2 m g \delta_{0}}{t(b-a)},
$$

where $G_{F}=$ fracture energy $(\mathrm{N} / \mathrm{m}), W_{0}=$ area under the force-deflection curve $(\mathrm{Nm}), m=$ weight of the beam between supports $(\mathrm{kg}), t=$ thickness; $b=$ depth; $\delta_{0}=$ Displacement corresponding to $P=0$ in the post peak region and $a=$ initial notch of the beam.

\subsection{Fracture toughness}

The fracture toughness $K_{I c}$ is calculated according to the RILEM (RILEM TC89-FMT, 1991) using the equation

$$
K_{I c}=3\left(P_{0}\right) \frac{S \sqrt{\pi} a g_{1}(\alpha)}{2 b^{2} t} \quad[\mathrm{MPa} \sqrt{m}]
$$


in which

$$
g_{1}(\alpha)=\frac{1.99-\alpha(1-\alpha)\left(2 \cdot 15-3.93 \alpha+2.7 \alpha^{2}\right)}{\sqrt{\pi}(1+2 \alpha)(1-\alpha)^{3 / 2}},
$$

where $\alpha=a / b, P_{0}=$ the measured maximum load $[\mathrm{N}]+$ self weight of the beam $[\mathrm{N}]$. The result correspond to the mean values of three tests. The critical energy release rate $G_{I c}$ is related to $K_{I c}$ as:

$$
G_{I c}=\left(K_{I c}\right)^{2} / E .
$$

\subsection{Intrinsic brittleness}

It is well known that the brittleness of concrete is characterized not only by the fracture toughness but also by a measure of the length of the fracture process zone. The smaller the length, more brittle is the material. According to the fictitious crack model (FCM) (Hillerborg et al 1976), the brittleness can be expressed:

$$
l_{c h}(\mathrm{~mm})=E G_{F} / f_{t}^{2},
$$

where $f_{t}$ is the tensile strength (MPa).

\subsection{Brittleness of concrete structure}

The brittle response of a concrete structure should not be confused with the intrinsic brittleness of concrete. The brittleness of concrete structural elements depends on their size. Small sized elements fail in ductile or plastic manner, while large sized elements of the same material fail in brittle and often in catastrophic manner. Bazant \& Pfeiffer (1987) and Bazant \& Kazemi (1990) proposed the structural brittleness number $1 / \beta$, which reflects the geometry and initial notch depth of the specimen, besides intrinsic brittleness of concrete and structural size. It is expressed by the following equation:

$$
\beta=\frac{b}{b_{o}},
$$

where $b$ is the characteristic dimension of the structure (the specimen height in this study) and $b_{o}$ is a coefficient determined experimentally.

\section{Experimental study}

\subsection{Material properties and mix proportions}

The cement used was 53 grade, having 3, 7 and 28 days strength as $263 \cdot 50,33 \cdot 20$, and $53.40 \mathrm{MPa}$, respectively. Crushed granite aggregates having maximum size of $16 \mathrm{~mm}$ were used. The specific gravity, dry-rodded unit weight, and water absorption of the coarse aggregate were $2.71,1,550 \mathrm{~kg} / \mathrm{m}^{3}$ and 0.5 by weight of the aggregate, respectively. River sand passing $4.75 \mathrm{~mm}$ seive was used. The specific gravity of the sand was 2.62 and the fineness modulus was $2 \cdot 48$. Class F fly ash from the thermal power plant near Raichur, India, was used. The quantities of materials for various mixes of SCC (SCC1, SCC2 and SCC3) are listed in table 1. 
Table 1. Quantities of material for $\mathrm{SCC} \mathrm{kg} / \mathrm{m}^{3}$.

\begin{tabular}{lccc}
\hline Materials & SCC1 & SCC2 & SCC3 \\
\hline Cement (kg) & 240 & 400 & 360 \\
Water (kg) & 220 & 180 & 190 \\
Fine Agg. (kg) & 900 & 900 & 900 \\
Coarse Agg. (kg) & 830 & 830 & 830 \\
Fly ash (kg) & 184 & 200 & 196 \\
Silica fume (kg) & 12 & 36 & 29 \\
HRWR (liter) & $2 \cdot 00$ & $4 \cdot 00$ & 3.50 \\
AEA (liter) & $0 \cdot 20$ & $0 \cdot 24$ & 0.40 \\
VMA (liter) & 0.50 & 1.50 & 1.25 \\
\end{tabular}

\section{Analysis of results}

\subsection{Fresh and mechanical properties of SCC}

The fresh and hardened properties of SCC were obtained by conducting tests and the results are listed in tables 2 and 3 .

Table 2. Fresh properties of SCC.

\begin{tabular}{lccc}
\hline Tests & SCC1 & SCC2 & SCC3 \\
\hline Slump Flow (mm) & 750 & 700 & 670 \\
T50 cm Slump Flow & 3 & 4 & 5 \\
J-ring (mm) & $3 \cdot 2$ & 3 & 8 \\
V-funnel (Sec) & 4 & 6 & 7 \\
V-funnel at T5 & 2 & 3 & 3 \\
L-box (H2/H1) & $0 \cdot 8$ & 1 & $0 \cdot 95$ \\
U-box (H2-H1) & 5 & 3 & 5 \\
Fill-box(\%) & 95 & 95 & 95 \\
\hline
\end{tabular}

Table 3. Mechanical properties of SCC.

\begin{tabular}{lccccc}
\hline Mix & $\begin{array}{c}\text { Density } \\
\mathrm{kg} / \mathrm{m}^{3}\end{array}$ & $\begin{array}{c}f_{c} \\
\mathrm{MPa}\end{array}$ & $\begin{array}{c}E \\
\mathrm{GPa}\end{array}$ & $\begin{array}{c}f_{t} \\
\mathrm{MPa}\end{array}$ & $\begin{array}{c}f_{r} \\
\mathrm{MPa}\end{array}$ \\
\hline SCC1 & 2044 & $17 \cdot 1$ & 17 & $1 \cdot 5$ & $2 \cdot 6$ \\
& 2074 & $16 \cdot 8$ & 17 & $1 \cdot 8$ & $2 \cdot 7$ \\
SCC2 & 2074 & $16 \cdot 1$ & $16 \cdot 5$ & $1 \cdot 7$ & $3 \cdot 0$ \\
& 2006 & $29 \cdot 8$ & 21 & $2 \cdot 7$ & $4 \cdot 2$ \\
& 1956 & $30 \cdot 4$ & 22 & $2 \cdot 7$ & $4 \cdot 2$ \\
SCC3 & 2010 & 31.4 & 22 & $2 \cdot 7$ & $4 \cdot 2$ \\
& 2163 & 45 & 28 & $3 \cdot 4$ & $6 \cdot 2$ \\
& 2133 & 46 & $28 \cdot 2$ & $3 \cdot 4$ & $6 \cdot 3$ \\
& 2104 & 43 & 27 & $3 \cdot 4$ & $5 \cdot 9$ \\
\hline
\end{tabular}




\subsection{Fracture energies $G_{F}, G_{f}$}

Geometrically similar specimens with three different sizes were used in order to allow the fracture energy evaluation through the SEM besides the work-of fracture method. To study the size effect, the beam specimens were loaded under three point bend condition. The beam specimens were geometrically similar in two-dimensions; viz. (i) the ratio of the span to the depth of the beam $(\mathrm{S} / \mathrm{b})$ was 4 for all the specimens; (ii) the ratio of the notch/depth $\left(a_{0} / b\right)$ equal to 0.33 and 0.01 for the (B1, B2, B4) and B3 respectively. The depth (b) of specimens were $50 \mathrm{~mm}, 100 \mathrm{~mm}$, and $200 \mathrm{~mm}$, with the lengths equal to $4 \cdot 2 \mathrm{~b}$, and span equal to $4 \mathrm{~b}$. The thickness of all beams was $50 \mathrm{~mm}$, which was determined by considering the maximum aggregate size $(16 \mathrm{~mm})$ to make sure that the thickness of the beams is larger than three times the maximum aggregate size. A total of 36 specimens, divided in three series of concrete batches (SCC1 to SCC3) were cast. Each series contained three specimens for each of the batches.

The equipment used to test the beam specimens was with three channels for data acquisition and a load cell of $50 \mathrm{kN}$ capacity. All the tests were conducted under the CMOD control. The notch was made at the time of casting using an acrylic plate with a thickness of $2 \mathrm{~mm}$.

From figure 1 in a typical force-deflection and force-CMOD curve for the specimens B2. Due to the CMOD control it is evident that, the pre-peak stiffness of force-displacement curve is more than that of force-CMOD.

Table 4 shows the corrected maximum loads for all the tested beams, which were obtained by adding half the beam self weight to the measured peak load, in order to consider the effect of the self weight of the specimen for fracture energy calculations (RILEM FMT 89, 1990).

The fracture energy, $G_{f}$, can be calculated by using equation (3) together with the values of $B, b_{0}$, and $E$ of each group of specimens with a specific $f_{c}$. The non-dimensional energy release rate $g(\alpha)$ is obtained from equation (5) for $g(0 \cdot 33)$ and $g(0 \cdot 01)$. The numerical value of $g^{\prime}(\alpha)$ in equation (4) is calculated using Matlab.

From the geometrically similar specimens in two-dimensions, fracture energies $G_{f}$ and $G_{F}$ are obtained by the work of fracture method and size effect model. It was seen that the values obtained for the fracture energy $G_{F}$ are greatly affected by the size of the specimen. The values of fracture energies $G_{F}, G_{f}$ according to the work of fracture and size effect model methods are listed in table 5. The standard requirements concerning the limiting values of the coefficient of variation of the slope of the regression line $\left(w_{A}\right)$ and the relative width of scatter-band $(\mathrm{m})$ and the values of $w_{A}$ and $\mathrm{m}$ should not exceed 0.10 and 0.20 respectively.
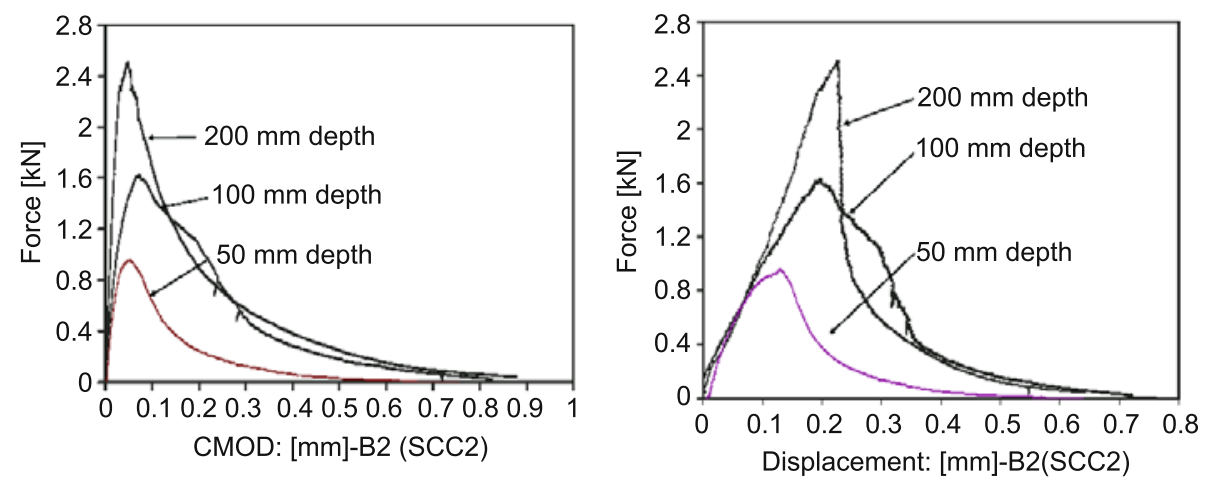

Figure 1. Typical force vs CMOD/displacement for mixes B2(SCC2). 
Table 4. Corrected maximum load for series B1 to B4, $S=4 b$.

\begin{tabular}{|c|c|c|c|c|c|c|c|c|c|c|c|}
\hline \multirow{3}{*}{$\begin{array}{l}\text { Series B, } \\
\text { Concrete }\end{array}$} & \multirow[b]{3}{*}{$f_{c}$} & \multirow[b]{3}{*}{$a / b$} & \multicolumn{9}{|c|}{$\begin{array}{c}\text { Corrected maximum load } P_{0}(\mathrm{~N}) \\
\text { Beam Depth b }(\mathrm{mm})\end{array}$} \\
\hline & & & \multicolumn{3}{|c|}{50} & \multicolumn{3}{|c|}{100} & \multicolumn{3}{|c|}{200} \\
\hline & & & 1 & 2 & 3 & 1 & 2 & 3 & 1 & 2 & 3 \\
\hline $\mathrm{B} 1(\mathrm{SCC} 1)$ & 15 & $0 \cdot 33$ & 745 & 707 & 726 & 1341 & 1431 & 1377 & 2286 & 2346 & 2386 \\
\hline $\mathrm{B} 2(\mathrm{SCC} 2)$ & 30 & 0.33 & 877 & 836 & 900 & 1560 & 1620 & 1540 & 2536 & 2636 & 2606 \\
\hline B3(SCC2) & 30 & 0 & 1973 & 2121 & 2065 & 3421 & 3441 & 3541 & 6200 & 6100 & 6050 \\
\hline $\mathrm{B} 4$ (SCC3) & 45 & $0 \cdot 33$ & 1072 & 1030 & 1017 & 1951 & 1881 & 1921 & 2786 & 2936 & 2836 \\
\hline
\end{tabular}

The following conclusions could be drawn from the table 5 for beams with and without notches under three point bend condition to investigate size effects: (i) values of $K_{I c}$ varies from 0.6 to $0.75 \mathrm{MPa} \sqrt{m}$, which is similar to previous investigations for light weight concrete on geometrically similar beams (Ta-peng \& Mei-Miao 1996). With an increase in compressive strength of SCC, there is an increase in the fracture toughness for notched and notchless beams. There is a significant difference between $K_{I c}$ of notched and notchless beams. It may be stated that in practice the beams are notchless and hence the value of $K_{I c}$ is over estimated which is also mentioned by Barr et al (1985); (ii) it is observed that the $G_{I c}$ normally varies between 17 and $40 \mathrm{~N} / \mathrm{m}$ for geometrically similar specimens (Bharatkumar et al 2005), while $G_{I c}$ varies between 10 and $25 \mathrm{~N} / \mathrm{m}$ for notched beam and between 2 and $5 \mathrm{~N} / \mathrm{m}$ for notchless beam. The variation of $K_{I c}$ is also reflected in the corresponding toughness value $G_{I c}$, since $K_{I c}$, and $G_{I c}$ are directly related as per equation (9); (iii) it is confirmed that, the fracture energy $G_{F}$ increases with an increase in the depth of beam as well as an increase in compressive strength and (iv) fracture energy $G_{f}$ and fracture process zone length $c_{f}$ are increased with decrease in compressive strength as pointed out by Bazant \& Pfeiffer (1987).

The size effect plot is shown in figure 2 for SCC beams with various compressive strengths, clearly show that, the present test results fall into the range of the transition zone between the fracture mechanics size effect and the horizontal line representing the strength criterion (Bazant \& Kazemi 1990). When fracture process zone is small, the failure pattern is more brittle and falls in the region of linear elastic fracture mechanics (LEFM). This means that SCC $45 \mathrm{MPa}$ is more brittle than SCC $15 \mathrm{MPa}$.

The test results of SCC are compared with the results from HPC and plotted in figure 2, for beams with depths (b) equal to $50 \mathrm{~mm}, 100 \mathrm{~mm}$ and $200 \mathrm{~mm}$ and compressive strength of $47 \mathrm{MPa}$. High performance concrete (Bharatkumar 2003) of $47 \mathrm{MPa}$ is relatively more brittle than SCC of $45 \mathrm{MPa}$ as can be seen clearly from figure 2. The point pertaining to HPC is to the right of SCC. It can be interpreted that, the SCC is less size dependent than HPC.

It can be seen that the test data lie close to the predictions of the size effect model. Figure 3 shows the best fits through the results obtained experimentally in a plot of $\log \left(\sigma_{N}\right) \mathrm{vs} \log (\mathrm{b})$. The curve of HPC tends to be asymptotic to LEFM behaviour much faster i.e. for smaller value of $\log (b)$ compared to that of SCC. The curve of SCC is flatter, with their tangents tending to become asymptotic to the LEFM line at larger values of $\log (b)$.

\subsection{Notchless SCC beams}

Notchless beams have not been tested sufficiently in the past. A very few data are available (Karihaloo \& Xiao 2002; Kim \& Eo 1990) for notchless beams. In the present work notchless 


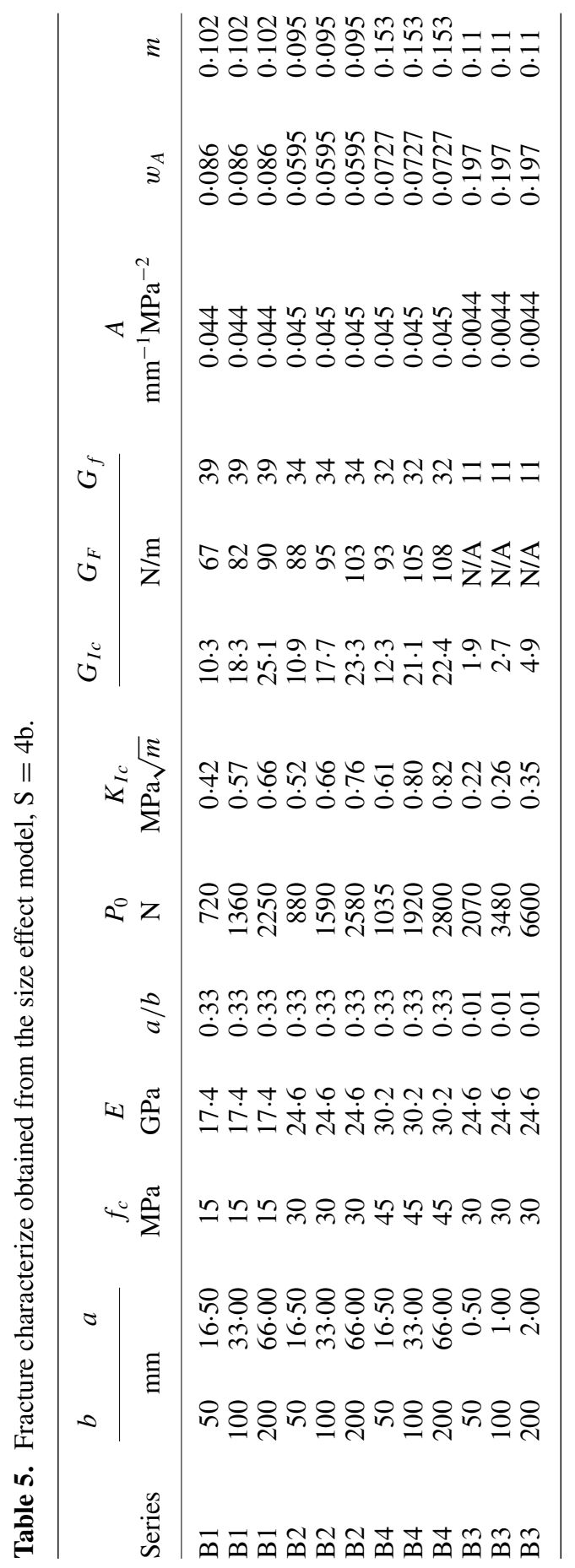




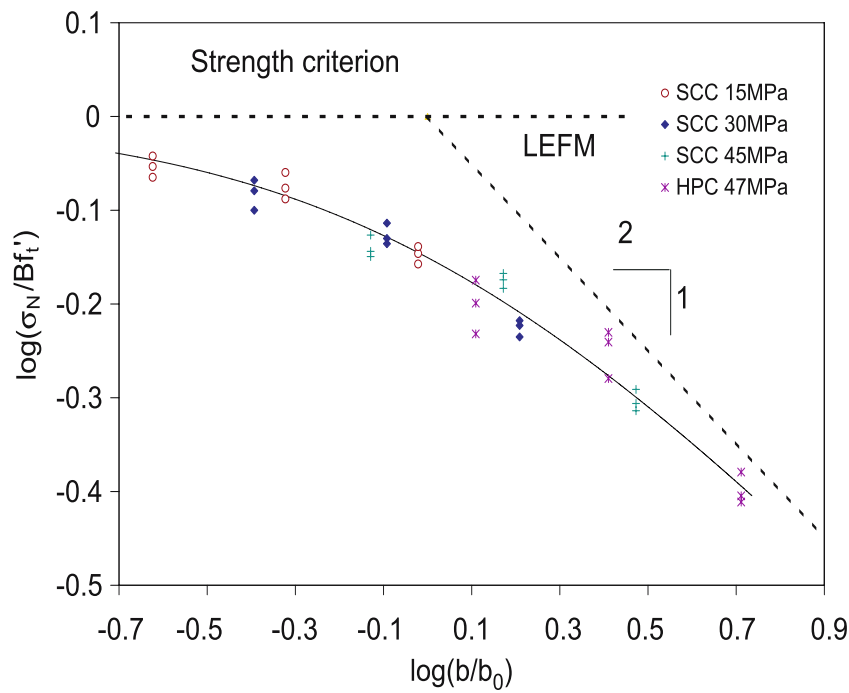

Figure 2. Comparisons of size effect plot for SCC and HPC (Raghu Prasad et al 2005).

SCC beams were tested and the results corresponding to compressive strength of $30 \mathrm{MPa}$ are presented in figures 4 and 5 . The $G_{f}$ has been obtained using the peak loads. It can be seen that the test data lie close to the predictions of the size effect law. From figure 5 it is seen that with increase in depth of beam, the decrease in nominal stress of notched beam is more when compared to that of a notchless beam. It could be due to the fact that notched beam in SEM is more brittle compared with a notchless beam. Results on SCC specimens show that the trend follow findings of (Karihaloo \& Xiao 2002) on high strength concrete (HSC), we observe from figure 5 that the curve is asymptotically touching the size effect plot of a notchless beam from below, while it reaches from above for a notched beam. Further, an interpretation from the laws of physics would be more appropriate to analyse the size effect plot. The interpretation

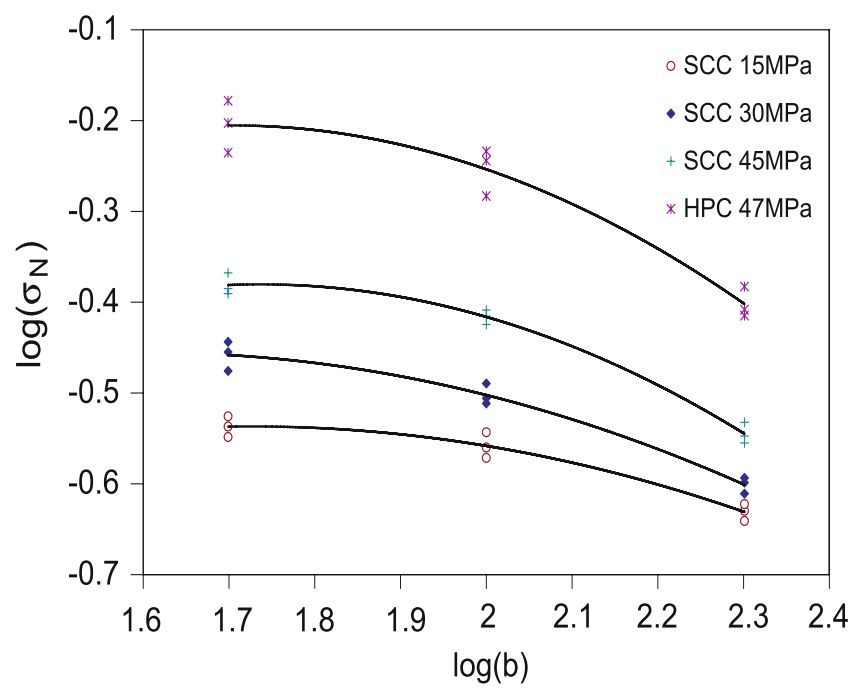

Figure 3. Comparative response of SCC and HPC for the size variation. 


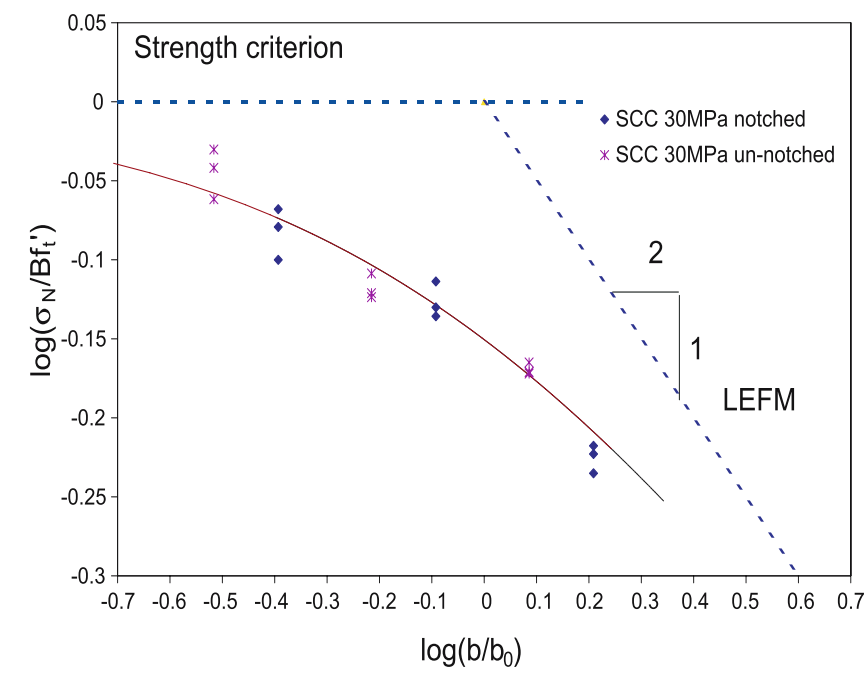

Figure 4. Size effect plot of notched and notchless beams for SCC.

could be the following; the curve asymptotically touches plot for SCC from below means that it is more ductile, because it tries to reach the LEFM behaviour at very large sizes. Such behaviour is not seen for HSC, which means that HSC is relatively more brittle.

\subsection{Intrinsic brittleness and brittleness of structure}

The intrinsic brittleness numbers based on FCM as per equation (10) and size effect model equation (4), were calculated accordingly and presented in table 6 . The $l_{c h}$ is found to vary between $266 \mathrm{~mm}$ to $446 \mathrm{~mm}$, which is in the range reported in literature (i.e. 200-500 for NC, 150-300 for HSC (Karihaloo 1995) and for HPC is 120-450 mm (Bharatkumar et al 2005)). It is seen that as the concrete strength increases $l_{c h}$ value decreases which indicates a trend towards brittle behaviour. The $l_{c h}$ also seems to depend on the size of the specimen and it increases with increase in size.

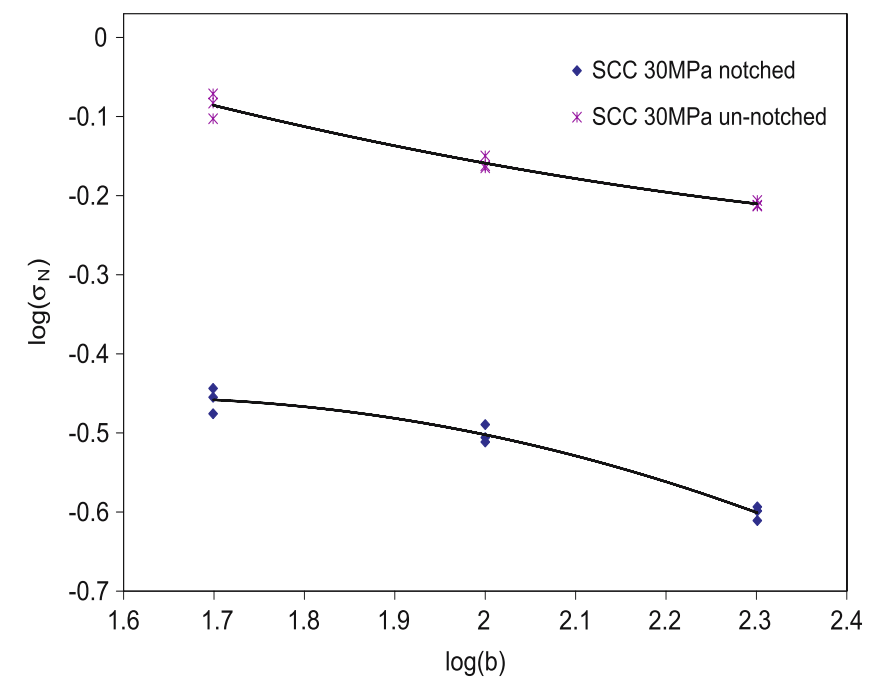

Figure 5. Comparative response of notched and notchless beams for SCC for the size variation. 
Table 6. Intrinsic brittleness values of SCC and brittleness of structure (B1, B2 and $\mathrm{B} 4, \mathrm{~S}=4 \mathrm{~b}$.

\begin{tabular}{|c|c|c|c|c|c|c|}
\hline Series & $b$ & $a$ & $f_{c}$ & $l_{c h}$ & $c_{f}$ & $\beta$ \\
\hline B1 & 50 & 16.50 & 15 & 332.7 & $41 \cdot 2$ & $0 \cdot 24$ \\
\hline B1 & 100 & 33.00 & 15 & $407 \cdot 2$ & $41 \cdot 2$ & 0.48 \\
\hline B1 & 200 & 66.00 & 15 & 446.9 & $41 \cdot 2$ & 0.95 \\
\hline B2 & 50 & $16 \cdot 50$ & 30 & 309.0 & 24.25 & 0.40 \\
\hline B2 & 100 & 33.00 & 30 & 333.5 & 24.25 & $0 \cdot 81$ \\
\hline B2 & 200 & 66.00 & 30 & $361 \cdot 6$ & 24.25 & 1.62 \\
\hline B4 & 50 & $16 \cdot 50$ & 45 & $266 \cdot 6$ & $13 \cdot 21$ & 0.74 \\
\hline B4 & 100 & 33.00 & 45 & 301.0 & $13 \cdot 21$ & 1.48 \\
\hline B4 & 200 & $66 \cdot 00$ & 45 & $309 \cdot 6$ & $13 \cdot 21$ & 2.97 \\
\hline
\end{tabular}

The relationship between the intrinsic brittleness of SCC for various depths of beams and the compressive strengths is derived from figure 6 and the following relationship between $l_{c h}$ and $f_{c}$ are obtained:

$$
l_{c h}=800 \alpha_{F}\left(f_{c}\right)^{-0 \cdot 3},
$$

where empirical constant, $\alpha_{F}=1,1.5$ and 1.3 for various depth of beam $50 \mathrm{~mm}, 100 \mathrm{~mm}$ and $200 \mathrm{~mm}$, respectively.

This relationship is similar to equation (13) which was proposed for HPC (Bharatkumar et al 2005)

$$
l_{c h}=780\left(f_{c}\right)^{-0 \cdot 3} \text {. }
$$

The comparison of $l_{c h}$ from SCC and HPC indicates that brittleness increases with increase in compressive strength, depth of beam and size of aggregate. It is also seen that the empirical

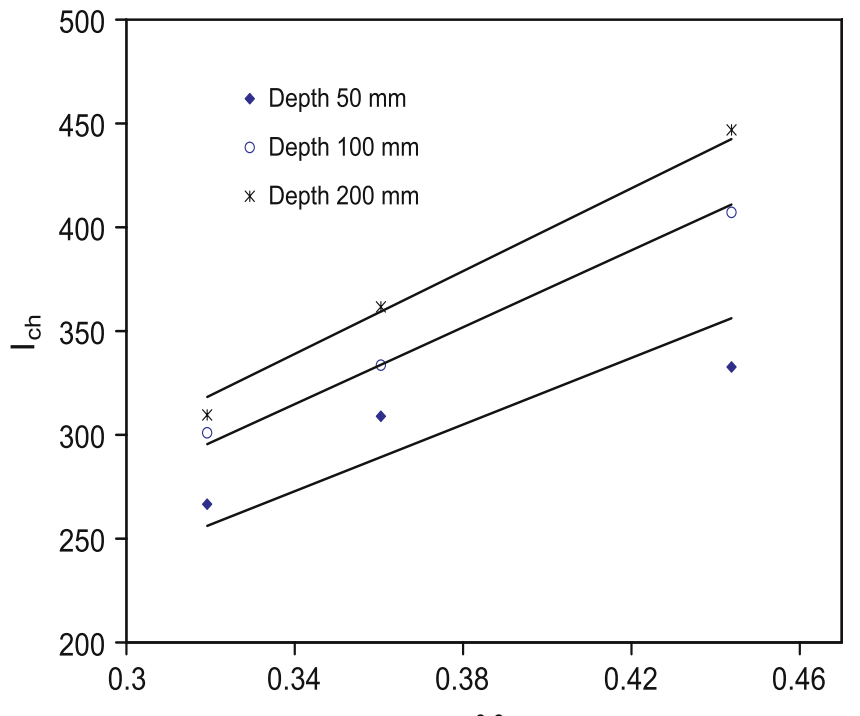

(fc) -0.3
Figure 6. Intrinsic brittleness of concrete beam of SCC for the size variation. 
Table 7. Values of $\beta$ corresponding to the structural design (Bazant \& Pfeiffer 1987; Bazant \& Kazemi 1990).

\begin{tabular}{ll}
\hline Values of $\beta$ & Structural design \\
\hline$\beta=1$ & strength and the LEFM approach \\
$\beta \leq 0 \cdot 1$ & plastic limit analysis \\
$\beta \geq 10$ & LEFM \\
$0 \cdot 1<\beta<10$ & nonlinear fracture mechanics \\
\hline
\end{tabular}

constant for SCC is more than that for HPC, which indicates the intrinsic brittleness, as per FCM is more in SCC compared to HPC.

Intrinsic brittleness of SCC as per size effect model is found to be varying from $13 \mathrm{~mm}$ to $41 \mathrm{~mm}$, The range reported in literature (Bazant \& Kazemi 1990; Gettu et al 1990; Bharatkumar et al 2005), show that the $c_{f}$ ranges between 6 and 15 for mortar, 10-25 for NC, 3-6 for HSC and 5-15 for HPC. The values obtained for SCC fall in this range. It is evident from table 6 that the fracture process zone reduces as the strength increases due to increase in density of concrete. The $c_{f}$ is found to be higher for SCC compared to HPC. This could be due to either SCC is more ductile or the length of fracture process zone is larger. As can be seen from literature, the values of $G_{f}$ and $c_{f}$ both together will increase or decrease. It can be seen from table 5 that the $c_{f}$ and $G_{f}$ both decrease with an increase in the compressive strength of SCC.

The brittleness of concrete structure based on equation (11) are given in table 6, which show that value $1 / \beta$ is decreasing with increase in the characteristic size (in present case the depth of beam). The values of $\beta$ for various design approaches are given in table 7 .

It is pointed out by (Bazant $\&$ Pfeiffer 1987) that $\beta$ is capable of characterizing the type of failure (brittle or ductile) regardless of structural geometry. It quantifies the proximity of the behaviour of a structure to LEFM and therefore $1 / \beta$ is convenient tool to measure the brittleness of structure or specimen.

\section{Conclusions}

Experiments were conducted to determine fracture properties of SCC notched and notchless beams under three-point bend condition. The main conclusions could be drawn from this study are:

(i) The results obtained by the work-of-fracture method show that fracture energy increases as the compressive strength of the concrete increases. Nevertheless, the results on fracture energy obtained by the SEM show a slight trend to decrease with increasing compressive strength.

(ii) On the size effect plot, the nominal strength of SCC beams shift from left to the right with increasing compressive strength of SCC, which means that an increasing compressive strength of SCC the failure mechanisms shift to brittle region of linear elastic fracture mechanics.

(iii) The asymptotic curve of SCC touching the plot from below means that it is more ductile, because it tries to reach the LEFM behaviour at larger sizes. Such behaviour is not seen for HSC, which means that HSC is relatively larger brittle. 
(iv) The values of characteristic length of SCC $l_{c h}$ and $c_{f}$ are more when compared with HPC, NC and HSC. It may be concluded that SCC is more ductile compared to other aforementioned concretes.

\section{Notation}

SCC Self consolidating concrete

$G_{F} \quad$ Fracture energy from work-of-fracture (N/m)

$G_{f} \quad$ Fracture energy from size effect model (N/m)

HPC High performance concrete

HRWR High range water reducing

VMA Viscosity modifying agent

NC Normal concrete

$K_{I c} \quad$ Critical stress intensity factor for mode I fracture (LEFM)

$l_{c h} \quad$ Characteristic length ( $\left.\mathrm{mm}\right)$

$G_{I c} \quad$ Critical energy release rate

SEM Size effect model

$b \quad$ Depth (mm)

$\sigma_{N} \quad$ Nominal stress at failure

$P_{u} \quad$ Ultimate load

$d \quad$ Length from bottom face of a specimen to roller axis ( $\mathrm{mm})$

$c_{f} \quad$ Length of fracture process zone $(\mathrm{mm})$

$g(\alpha) \quad$ Crack opening profile function

$\alpha \quad$ Relative notch depth ratio

A Slope of regression plot

$1 / \beta \quad$ Structural brittleness number

$a \quad$ initial notch of the beam (mm)

LEFM Linear elastic fracture mechanics

$W_{0} \quad$ Area under the force-deflection curve $(\mathrm{Nm})$

$m \quad$ Weight of the beam between supports $(\mathrm{kg})$, Scatter-band

$t \quad$ Thickness (mm)

$\delta_{0} \quad$ Displacement corresponding to $P=0$ in the post peak region

$P_{0} \quad$ Maximum load $[\mathrm{N}]+$ self weight of the beam [N]

FCM Fictitious crack model

$1 / \beta \quad$ Structural brittleness number

$f_{c} \quad$ Compressive strength of concrete (MPa)

$f_{r} \quad$ Modulus of rupture (MPa)

$f_{t} \quad$ Splitting Tensile Strength (MPa)

E Young's modulus of elasticity (GPa)

CMOD Crack mouth opening displacement

$S \quad$ Span

AEA Air entraining admixture

HSC High strength concrete

$\mathrm{MPa}$ Mega Pascal

$W_{A} \quad$ Coefficient of variation of the slope of the regression line

(m) Width of scatter-band 


\section{References}

Albiero E 2001 SCC: Special concrete for the foundation pier of barletta mill. Production Technol. $22-25$

Amparano F E, Xi Y, Roh Y S 2000 Experimental study on the effect of aggregate content on fracture behaviour of concrete. Eng. Frac. Mech. 67(1): 65-84

Appa Rao G, Raghu Prasad B K 2002 Fracture energy and softening behaviour of high-strength concrete. Cement and Concrete Res. 32(2): 247-252

Barr B, Hasso E B D, Sabir B 1985 The effect of test specimen size on the fracture toughness of concrete. Cement and Concrete Res. 15(5): 833-841

Bazant Z P, Giraudon E B 2002 Statistical prediction of fracture parameters of concrete and implications for choice of testing standard. Cement and Concrete Res. 32(4): 529-556

Bazant Z, Kazemi M 1990 Determination of fracture energy, process zone length and brittleness number from size effect, with application to rock and concrete. Int. J. Fract. 40(2): 111-131

Bazant Z, Pfeiffer P 1987 Determination of fracture energy from size effect and brittleness number. ACI Mater. J. 84(6): 453-480

Belhamel F, Hisham K, Kharchi F 2002 Experimental method for the determination of the failure energy of ordinary concretes. Mater. Struct. 35(3): 182-188

Bharatkumar B H, Prasad B K R, Murthy D S R, Narayanan R, Gopalakrishnan S 2005 Effect of fly ash and slag on the fracture characteristics of high performance concrete. Mater. Struct. 38(1): 63-72

Bharatkumar B 2003 Fracture characteristics and behaviour of high performance concrete (plain and reinforced). $\mathrm{PhD}$ thesis, IISc, India 235

Biolzi L, Guerrini G L, Rosati G 1997 Overall structural behaviour of high strength concrete specimens. Constr. Build. Mater. 11(1): 57-63

Bury M A, Christensen B J 2002 The role of innovative chemical admixtures in producing selfconsolidating concrete. Proc 1st Conf SCC, Rosemont, Illinois 137-141

Druta C 2003, Tensile strength and bonding characteristics of self-compacting concrete. MSc thesis, Louisiana State Universityand 115

Elices M, Guinea G, Planas J 1992 Measurement of the fracture energy using three-point bend tests: Part 3-influence of cutting the $p-\delta$ tail. Mater. Struct. 25(4): 327-334

Elices M, Guinea G, Planas J 1997 On the measurement of concrete fracture energy using three-point bend tests. Mater. Struct. 30(6): 375-376

Gettu R, Bažant Z P, Karr M E 1990 Fracture properties and brittliness of high-strength concrete. ACI, Mater. J. 87(6): 608-618

Giaccio G, Rocco C, Zerbino R 1993 The fracture energy $\left(g_{f}\right)$ of high-strength concretes. Mater. Struct. 26(161): 381-386

Guinea G, Planas J, Elices M 1992 Measurement of the fracture energy using three-point bend tests: Part i-influence of experimental procedures. Mater. Struct. 25(4): 212-218

Haidar K, Cabor G P 2002 Influence of porosity on fracture characteristics in mortar structures. Proc 15th ASCE Eng. Mech. New York 1-8

Hillerborg A, Modeer M, Petersson P 1976 Analysis of crack formation and crack growth in concrete by means of fracture mechanics and finite elements. Cement and Concrete Res. 6(6): 773-782

Karihaloo B 1995 Fracture mechanics and structural concrete. (UK: Longman Scientific and technical)

Karihaloo B, Xiao Q 2002 Size effect in the strength of concrete structures. J. Ind. Nat. Acad. Sci. 27(4): 449-459

Kim J K, Eo S H 1990 Size effect in concrete specimens with dissimilar initial cracks. Mag. Con. Res. 42(153): 233-238

Kishi T, Hosoda A, Gurung C B, Kittiwuttichusinp S 2000 Effect of drying/autogenous shrinkage on ductility/fracture mode of beam and self-repairing function of expansive agent. Proc. JCI 22(3): 511-516

Mata L A 2004 Implementation of self-consolidating concrete (SCC) pre-stressed concrete girders. M.Sc Thesis, North Carolina State University 119 
Mindess S 1984 The effect of specimen size on the fracture energy of concrete. Cement and Concrete Res. 14(3): 431-436

NT Build 491: 1999 Fracture energy (mode i)-three-point bend tests on notched beams. Nordtest Method 1-4. Available online, http://www.nordicinnovation.net/nordtestfiler/build491.pdf

Perdikaris P C, Romeo A 1995 Size effect on fracture energy of concrete and stability issues in threepoint bending fracture toughness testing. ACI, Mater. J. 92(5): 483-496

Petersson P 1980a Fracture energy of concrete; method of determination. Cement and Concrete Res. 10(1): 78-89

Petersson P 1980b Fracture energy of concrete: Practical performance and experimental results. Cement and Concrete Res. 10(1): 91-101

Raghu Prasad B K, Bharatkumar B H, Murthy D S R, Narayanan R, Gopalakrishnan S 2005 Fracture mechanics model for analysis of plain and reinforced high-performance concrete beams. ASCE, Eng. Mech. J. 131(8): 831-838

RILEM FMC-50: 1985 Determination of the fracture energy of mortar and concrete by means of three-point bend tests on notched beams. Mater. Struct. 18(4): 287-290

RILEM FMT 89: 1990 Size-effect method for determining fracture energy and process zone size of concrete. Mater. Struct. 23(6): 461-465

RILEM TC89-FMT: 1991 Determination of fracture parameters $\left(k_{I C}\right.$ and $\left.c t o d_{c}\right)$ of plain concrete using three-point bend tests. Mater. Struct. 23(6): 457-460

Strange P C, Bryant A H 1979 The role of aggregate in the fracture of concrete. J. Mater. Sci. 14(8): $1863-1868$

Ta-Peng C, Mei-Miao S 1996 Fracture properties of lightweight concrete. Cement and Concrete Res. 26(2): 181-188

Tang T, Ouyang C, Shah S P 1996 Simple method for determining material fracture parameters from peak loads. ACI, Mater. J. 93(2): 147-157

Wittmann F H 2002 Crack formation and fracture energy of normal and high strength concrete. J. Ind. Nat. Acad. Sci. 27(4): 413-423 